\title{
Exploring agency beyond humans: the compatibility of Actor-Network Theory (ANT) and resilience thinking
}

\author{
Angga Dwiartama ${ }^{1,2}$ and Christopher Rosin ${ }^{1}$
}

\begin{abstract}
At first glance, the compatibility of social theory and resilience thinking is not entirely evident, in part because the ontology of the former is rooted in social interactions among human beings rather than ecological process. Despite this difference, resilience thinking engages with particular aspects of social organization that have generated intense debates within social science, namely the role of humans as integral elements of social-ecological systems and the processes through which given social structures (including material relations) are either maintained or transformed. Among social theoretical approaches, Actor-Network Theory (ANT) is noted for its distinctive approach to these aspects. ANT proposes that human and nonhuman components (both referred to as actants) have the same capacity to influence the development of social-ecological systems (represented as actor-networks) by enacting relations and enrolling other actors. We explore the notion of agency that is employed in resilience thinking and ANT in order to extend our understandings of human-environment relationships through complementary insights from each approach. The discussion is illustrated by reference to ongoing assessment of resilience as it is experienced and expressed in two distinctive agricultural production systems: Indonesian rice and New Zealand kiwifruit. We conclude by establishing the potential for ANT to provide more profound theoretical conceptualizations of agency, both human and nonhuman, in analyses of social ecological systems.
\end{abstract}

Key Words: actor-network; kiwifruit; nonhuman agency; relationality; rice

\section{INTRODUCTION}

Resilience thinking provides a valuable means to assess and act on the capacity of a social-ecological system (SES) to retain functions and support its components. Social science theory and explanation can inform this assessment by providing a more comprehensive understanding of human participation and interaction within these systems (Westley et al. 2002, Cote and Nightingale 2012). We examine the concept of agency, which in social sciences is used to distinguish the capacity for an agent (usually a human) to influence broader social relations (or structures) or to actively control its own well-being (Lister 2004, Brown and Westaway 2011). Agency, in other words, represents the attempt to conceive of social action and the origins and process of societal change as well as to assign responsibility for the implications of such action and change. Understood in this manner, the concept refers not to any identified action or activity but more specifically the capacity to initiate desired or preferred courses of action. Early conceptions of agency positioned it in an oppositional dichotomy with structure (Bottomore and Nisbet 1978), the latter concept representing the tendency for existing conventions of interaction and social ordering to constrain the actions of individuals. More recent theorizing moves away from determinism by attempting to bridge the distinction between the two concepts (Bourdieu 1977, Giddens 1984).

Social science encompasses a broad set of disciplinary approaches to the social, which have elicited an equally diverse set of conceptions of agency (e.g., Long and van der Ploeg 1994). The predominant factor by which these approaches are differentiated is the relative capacity for change in the social structure. These can range from structural representations in which the permanence of social structures constrain and direct society with little impact from individual action (akin to self-organization in ecological systems) to more individualist approaches in which structures are constantly being created and recreated through the actions of individuals and their interactions with others. More recently, social theory has emerged that attempts to incorporate both the reinforcing capacity of structures and the contingency and emergence of individuals. We examine the implications of such theorization on understandings of the role of actors and agency in driving change and/or shaping complexity in social-ecological systems. Our approach follows the influential conceptualization of agency used in Actor-Network Theory (ANT) as developed by Latour (1987, 2005), Callon (1986) and Law (1992).

The concept of agency within ANT, we argue, offers several advantages to resilience thinking, both in its analytical focus and by offering a more encompassing concept of agency that extends beyond human intentionality. In comparison to other social science perspectives that emphasize either specific sites of action (e.g., institutions or markets) or aspects of social interaction (e.g., power), ANT focuses on the relationships in which agents participate and how these are used to influence the shape of a network of related relationships. This focus corresponds well with that on process in a social-ecological system (SES) (Bohle et al. 2009) and is more sensitive to emergent properties within systems (Levin 1999). ANT is also distinguished by its attribution of agency to nonhumans, including animals, materials, ideas, and concepts, acknowledging the ability of any entity (or actant) to make itself indispensable to its relationships with others and, by extension, to the continuation of the network. Within this conception of agency it becomes necessary to shift the focus from human intentionality as the principle influence on resilience and to recognize the diverse components of an SES (including plants and animals as well as minerals and climate) as system-forming entities. As a result, we challenge generalized recommendations for building resilience to take into account the particularities and contingencies introduced to the SES by nonhuman components. 


\section{AGENCY IN RESILIENCE THINKING}

In the years since Holling's seminal paper on ecosystem resilience was published in 1973, interests in resilience thinking have continued to grow, with the scope of its influence stretching into diverse disciplines (Gunderson and Holling 2002, Folke 2006), many of which seek to position society as a prominent component. This integration of a specifically social dimension within resilience thinking has been the source of much debate in the literature, particularly surrounding the nature-society (Davidson-Hunt and Berkes 2002) and the structure-agency dichotomies (Westley et al. 2002). A handful of studies (e.g., Allison and Hobbs 2004, Olsson et al. 2004, Walker et al. 2004) have attempted to resolve the dichotomy between nature and society by proposing the concept of social-ecological systems (SESs). An SES forms a single unit of analysis that unveils new emergent properties which remained unobserved in studies of social or ecological systems alone.

However, several scholars argue that there is more to the social system beyond the deterministic biotic-abiotic relationships represented in ecological systems, an omission that is particularly evident in the consideration of resilience as a system property. Westley et al. (2002) and Davidson (2010), for instance, reveal that social systems comprise features such as symbolic constructions and reflexivity that are unique to humans. They thus argue that a structuralist perspective of self-organizing systems is not adequate to comprehend the complexity beneath social resilience. On a similar basis, Bohle et al. (2009) criticize resilience as a system property, raising the concern that resilience is sometimes negative and, even worse, abusive. They illustrate this through the case of the urban food system in Dhaka, Bangladesh. While the food system appears to be resilient (and helps to legitimize government policies), the active choices and efforts of the urban poor to shape that resilience are often not taken into account.

These observations challenge system resilience thinkers to employ a different view of resilience as advocated in the study of natural hazard (Adger 2000) and social psychology (Walsh 1998). From the study of vulnerability, Neil Adger argues that resilience is "the ability of groups or communities to cope with external stress and disturbances as a result of social, political, and environmental changes" (Adger 2000:347). Similarly, from social psychology, resilience is defined as "... an active process of endurance, selfrighting, and growth in response to crisis and challenge" (Walsh 1998:4). Both of these definitions imply an active role for humans (as individuals and collectives) to act beyond the given social structure; a capacity often referred to as agency (Bohle et al. 2009, Coulthard 2012, Berkes and Ross 2013). Agency allows humans to learn from and reflect on experiences, forecast trajectories of future development, and by doing so, increase the resilience of their livelihood.

The concept of agency within the later evolution of resilience thinking (Pelling and Manuel-Navarrete 2011, Coulthard 2012, Berkes and Ross 2013) was derived from various social discourses, such as a well-being approach (Lister 2004), social cognitive theory (Bandura 2001), theory of structuration (Giddens 1984), and development sociology (Long and van der Ploeg 1994). From a well-being perspective, agency is realized by an autonomous and purposive actor-which is attributed solely to humans. Lister (2004) describes different types of agency. Whereas personal agency comes from everyday decision-making processes in people's lives and personal choices on particular circumstances in life, political agency entails the ability of humans (individuals or collectives) to affect social processes. This intentionality gives humans an active role in their process of adapting to changes and being resilient instead of being the passive subjects of shocks (Bohle et al. 2009, Coulthard 2012). In development sociology or social cognitive theory, agency comes from the capacity of humans to act and change a state of affairs within the society (Long and van der Ploeg 1994) or the interactions and synergy between members of a community (Bandura 2001). This suggests that agency and adaptive capacity require social relations and networks of actors, as depicted by Coulthard (2012) and Berkes and Ross (2013) in their studies on the resilience of a fishing society and community resilience, respectively.

Ross and Berkes (2013) propose the need for a broader understanding of agency that is not confined to individual actions but includes, referring to Bandura (2001), a form of collective agency that emerges from "... interactive, co-ordinative and synergistic dynamics of their transactions" (Bandura 2001:75-76, Ross and Berkes 2013:26). Bandura (2001) further asserts that individual agency can be enhanced or constrained by others. Collective agency is thus an emergent group-property that comes from interrelationships between its members. However, if collective agency can be manifest within the social, does the same hold true of human-nature relationships? In other words, can the relationality between humans and their nonhuman surroundings -which to some extent also limit and enhance human decisions -also produce a form of heterogeneous collective agency?

This leads us to comprehend agency as something more complex than pure intentionality. Within the theory of structuration, Giddens (1984) moves beyond the structure-agency dualism through what he calls the duality of structure; i.e., agents are constrained by, and at the same time reproduce, the structure to which they are bound. Structures may assume the form of rules and resources, in both material and nonmaterial sources of power. Pelling and Manuel-Navarrete (2011) attempt to link this duality of structure to the SES by illustrating how resilience is influenced by the interplay between the dynamics of the social structure and the agency of social capital. A noteworthy implication of their analysis is that, in making sense of resilience from an actororiented approach, agency cannot be enacted solely through human intentionality, as it is also reliant to some extent on the actor's relationality to the material components of society.

We address the question of whether agency is more appropriately conceived as a network of social relations rather than as intentionality, and - by extension - if intentionality is seen as a result of these complex relations, can material objects also have agency? We thus explore the distinct understandings of socialecological resilience that emerge when we view nonhumans as active agents that can enhance or hinder the resilience process. We start with a theoretical rationale to support this perspective, which originates mainly from a prominent theory in the social studies of science and technology, namely ANT. We explore the way in which ANT may offer alternative insights into our usual perceptions of resilience by assigning agency to the more-thanhuman (Braun 2005). We then substantiate the argument through empirical case studies of rice agriculture in Indonesia and the New Zealand kiwifruit industry. 


\section{THE AGENCY OF NONHUMANS: INSIGHTS FROM ACTOR-NETWORK THEORY}

Actor-network theory asserts that agency is manifest only in the relation of actors to each other. Within this framing, material objects exert agency in a similar manner to humans. In this sense, the conception of agency in ANT is distinct from that of other social approaches. In order to better understand agency through the lens of ANT, we must first more deeply interrogate our perceptions of the complexity of relationality by shifting our perspective from a system to a network. Chunglin Kwa (2002) distinguishes two conceptions of complexity based on their respective ways of seeing society and nature: as a self-regulating system and as a network of heterogeneous associations. The former looks to integrate individuals within a single entity with self-regulating properties. It recognizes that a group of individuals creates a unity at a higher level of organization. The selfregulating mechanism implies that any system seeks equilibrium and orients towards maturity or climax.

A systems approach to resilience thinking aligns with this conception of complexity (Walker et al. 2004). Within this perspective, an SES arguably demonstrates the properties and dynamics of a self-regulating system. For example, the integration of individuals and smaller systems into a larger system at a higher scale is clearly represented by panarchy (Gunderson and Holling 2002). Furthermore, the metaphor of the adaptive cycle illustrates the development of an SES according to a particular pattern of growth, climax, collapse, and reorganization, somewhat similar to the metaphor of "superorganism" in Clements's (1916) theory of successions. From these characteristics, it follows that social dynamics are understood as mechanisms of a complex social system comprised of individuals (or actors) who self-regulate and move towards a higher system's order.

Kwa (2002), however, asserts that a system is not the only means for understanding complexity, proposing that it is better viewed not as a unity but as a collection of structures - a group of individuals cooperating as table companions. Unlike a system, no stable pattern emerges from the connection between individuals. The materials comprising a larger association engage in free and random combinations with others and fluidly flow across all directions. In relation to nature, this conception emerges in the critique of Clements' superorganism by ecologists like Henry Gleason and Paul Colinvaux. Gleason argues that “... an association is not an organism, scarcely even a vegetational unit, but merely a coincidence"(Gleason 1926:16). Likewise, Colinvaux (1973) refutes the existence of self-organizing properties, arguing that we are merely observing the consequences of the various adaptive strategies of individual organisms.

ANT reflects this latter conception of complexity. It employs a post-structuralist perspective of the social, examining a society that consists not only of people but also of the associations between people and the material objects surrounding them (Latour 2005). It asserts that any entity that exists within the social system is meaningful because of the network of relationships it shapes with others, instead of its existence per se. To account for this attribution of meaning, ANT uses the term actant to distinguish its conception of an actor as embedded within network relationships from a more traditional conception (commonly defined by individuality and intentionality). An actant is thus defined as "an effect generated by a network of heterogeneous, interacting, materials" (Law 1992:383). The implications of this perspective can be demonstrated with the example of a human who, as a (food) consumer, is formed by his/ her connection to retailers and farmers and to the foods he/she eats. Without these other actants, the meaning of the human as consumer perishes. This is also true of nonhuman actants such as nature, commodity, technology, or even ideas and knowledge.

Actants are constantly reforming networks, and by so doing, position themselves in different and changing roles. In a society, human and nonhuman actants develop a social ordering similar to the structure found in other social theories. Yet, these modes of social ordering are not constant, varying in time and space. The rigidity or fluidity of the structure within these networks depends on the ways in which the actants continuously form networks among each other (Murdoch 1998). ANT argues that power, domination, and structure are processes resulting from actor-network relationships, rather than given systems attributes (Law 1992). For the same reason, resilience is considered a process within an actor-network perspective - similar to the agency-based approach in the new wave of resilience thinking (Bohle et al. 2009).

The agency that ANT advocates is, however, somewhat different from the concept of agency within resilience thinking and SESs. Within ANT, agency is extended beyond human intentionality. An agent is plainly understood as "any thing that does modify a state of affairs by making a difference" (Latour 2005:71). Such a claim asserts that what matters is not the intentionality itself but how intentionality is shaped (allowed, encouraged, blocked, rendered possible) by an extension of causal relations between humans and nonhumans. From an ANT perspective, rather than being passive resources at the disposal of humans, nonhumans are active, vibrant agents that also exert power. Jane Bennett (2007:134) describes this form of agency as "... a force distributed across multiple, overlapping bodies, disseminated in degreesrather than the capacity of a unitary subject of consciousness." As Bruno Latour (2005:72) explains:
ANT is not the empty claim that objects do things "instead" of human actors: it simply says that no science of the social can even begin if the question of who and what participates in the action is not first of all thoroughly explored, even though it might mean letting elements in which, for lack of a better term, we would call nonhumans. [...] The project of ANT is simply to extend the list and modify the shapes and figures of those assembled as participants and to design a way to make them act as a durable whole.

The implications of this shift in the understanding of agency from human intentionality to heterogeneous association that includes the materiality of nonhumans have been addressed by several authors. For instance, Bennett (2007) illustrates how foodstuffs such as dietary fat, vegetables, and alcohol act as quasi-agents that affect not only the human body (which is often taken for granted as a form of agency) but also moods and cognitive processes. Even more so, they take part in the emergence of civic movements like Slow Food. Law (1986) conducted a historical 
Table 1. Three different perspectives in understanding resilience.

\begin{tabular}{|c|c|c|c|}
\hline & System perspective & Human agency perspective & Actor-network perspective \\
\hline $\begin{array}{l}\text { Definition of } \\
\text { resilience }\end{array}$ & $\begin{array}{l}\text { "the capacity of a system to absorb } \\
\text { disturbance and reorganize while } \\
\text { undergoing change so as to still retain } \\
\text { essentially the same function, structure, } \\
\text { identity, and feedbacks." (Walker et al. } \\
\text { 2004:2) }\end{array}$ & $\begin{array}{l}\text { "the ability of groups or communities to } \\
\text { cope with external stress and disturbances } \\
\text { as a result of social, political, and } \\
\text { environmental changes" (Adger 2000:347) }\end{array}$ & $\begin{array}{l}\text { "an effect generated by a network of } \\
\text { heterogeneous, interacting, materials" } \\
\text { (Law 1992:383) }\end{array}$ \\
\hline $\begin{array}{l}\text { Focus of } \\
\text { attention }\end{array}$ & $\begin{array}{c}\text { Adaptive cycle, cross-scale dynamics, } \\
\text { slow and fast variables (Gunderson and } \\
\text { Holling 2002) }\end{array}$ & $\begin{array}{l}\text { Human agency (Bohle et al. 2009, } \\
\text { Coulthard 2012), Components in building } \\
\text { resilience (Folke et al. 2003, Berkes and } \\
\text { Ross 2013) }\end{array}$ & $\begin{array}{c}\text { Nonhuman/relational agency (Bennett } \\
\text { 2007), fluidity (de Laet and Mol 2000), } \\
\text { durability (Law 1986) }\end{array}$ \\
\hline $\begin{array}{l}\text { Possible } \\
\text { strategies to } \\
\text { employ }\end{array}$ & $\begin{array}{l}\text { Identifying threshold of the system and } \\
\text { shocks that might cause the system to } \\
\text { lose its resilience (Walker et al. 2002) }\end{array}$ & $\begin{array}{l}\text { Identifying and nurturing components of } \\
\text { community resilience (e.g., leadership, } \\
\text { social capital) (Berkes and Ross 2013) }\end{array}$ & $\begin{array}{l}\text { Taking into account and modifying the } \\
\text { specific relations between humans and } \\
\text { nonhumans to build resilience }\end{array}$ \\
\hline
\end{tabular}

analysis of the extension of Portugal's power over 150 years of naval exploration in which he assigns equal importance to the agency of ships, spices, and documents as to that of humans. These materials attracted, elongated, mobilized, and rendered durable to the Portuguese exercise of power. They are, too, agents without which the agency of humans is meaningless. In their investigation of the Zimbabwe Bush Pump, de Laet and Mol (2000) demonstrate the influence of networks of human and nonhuman entities on technological adaptation and social transformation. The design of the water pump (brightly colored, locally made, and easily adjusted) encourages its adoption, requires community cohesion to operate, and helps build the nation through a good supply of clean water. The essential shared element of these views of agency is an acknowledgement of the importance of interrelationships between human and other (nonhuman) components (e.g., nature, technology, infrastructures) in the analysis.

In summary, an approach to agency as proposed in ANT offers complementary insights into SESs through two propositions. First, resilience is seen as an ongoing process (as opposed to an end point or terminal goal) generated by interacting components that simultaneously configure and disfigure the existing relationships in their effort to remain indispensable to others. This view requires us to shift our perspective from system-based (emphasizing the emergence of stable patterns and self-regulating mechanisms) to network-based (focusing on contingency as part of the equation). Second, in order to think about resilience in this manner, we need to account not only for human agency but also for that inherent to the materiality of nonhumans as expressed in the interactions between humans and the material objects surrounding them. Although resilience thinking has, to some extent, addressed the interactions between social and ecological components of an SES in terms of system dynamics, the understanding of these dynamics is still constrained by the assumption that patterned trajectories emerge from the structure (as a form of self-organization) and the influence of humans, as sole agents, on the system. ANT, however, offers an alternative understanding of these dynamics, as being the result of contingent and unpatterned interactions among humans and the materiality of the nonhumans. Table 1 elaborates the differences between these perspectives and the way in which each offers complementary insight into defining resilience and formulating possible policy and strategy implications that emerge from each of these perspectives.

Having established the distinct implications of different conceptualizations of agency, we now present an application of the ANT perspective to the assessment of two contrasting agricultural systems: Indonesia's rice agriculture and the New Zealand kiwifruit industry. This assessment is based on data collected from primary (semi-structured interviews with diverse participants within the respective SESs) and secondary sources (government reports and academic publications) during doctoral research conducted by one of the authors between January and July 2012. It is noteworthy that both of the systems face similar types of environmental (climate, pest, and disease) and economic (price fluctuation) shocks as well as longer term trends in the economic viability and social acceptability of agricultural practice. The commitment of the human participants to maintaining and improving the potential of the systems suggests that these are desirable (Walker et al. 2004), especially where the rice and kiwifruit produced are an integral part of their culture and lifestyle aspirations. For the purposes of our argument, we concentrate on the human-nonhuman relations at the level of food production systems, although this is informed by a broader understanding of interactions within and between systems (from local to global, everyday practice to geopolitics) as elaborated in Dwiartama (2014). Thus, the focus of our analysis is to draw complementary insights from the two distinctive systems that can inform efforts to build resilience of agri-food systems more generally.

\section{RESILIENCE AND HUMAN INTENTIONALITY IN RICE AND KIWIFRUIT}

\section{Indonesia's rice agriculture}

In Indonesia, rice production and consumption are integral elements of society and culture. Rice consumption has been increasing since 1970 (Gerard et al. 2001) and currently supplies $47 \%$ of the country's total calorie intake (BPS 2013). Rice is the main commodity for the $42 \%$ of Indonesia's 237 million people 
who are farmers. In 2012, the total area of rice agriculture reached 13 million hectares with total production of up to 69 million tons of rice (BPS 2013). In addition to its role as a staple food, rice is an integral part of Indonesian culture and identity, as evidenced in their mythology and worldview (Wessing 1998, Soemarwoto 2007). The importance of rice as both a food and a source of income in Indonesia raises both the awareness of the precarious resilience of rice agriculture and the efforts put into maintaining a more resilient SES in Indonesia.

Historically, Indonesia's rice production system has endured many perturbations and undergone transformations during which it has shown remarkable resilience. Rice cultivation started millennia ago and, at least in the past four centuries, has undergone significant evolutions through commercialization (Latham and Neal 1983), decommercialization (Husken 1989), market disintegration (Marks 2010), industrialization (Herdt and Capule 1983), and periods of constant growth (Dawe 2002), in a manner that resembles repeated and prolonged adaptive cycles. The shocks to which the rice system responds appear in multiple dimensions. A significant source of disturbance involves the political economic role of the commodity within Asia. Indonesia is one of the largest rice producers and importers in Asia; therefore, economic and political situations in the country can profoundly influence the thin and volatile international rice market (Dawe 2002). Price fluctuations for rice also seriously impact the livelihood of most farmers and urban poor in Indonesia (Irhamni and Nuryakin 2009). On the other hand, environmental problems such as El Niño-related drought and pest outbreak have been shown to exacerbate the effect of price fluctuations, especially at the farm level (Rölling and van de Fliert 1994, Keil et al. 2008). Despite such shocks, however, the system has maintained its function of providing food for the populous country.

From a system perspective, it is possible to construct historical narratives that clearly demonstrate the contribution of human intentionality to the resilience of Indonesia's rice agriculture. Here, it is interesting to see how resilience is enacted as an active adaptation process at individual and community levels. In some regions, farmers are combining the scientific knowledge acquired from research centers (for example, integrated pest management) with their own local knowledge (mixed-crop farming system) to ensure that the farming system is resilient in the face of environmental shocks (e.g., Fernando 1993, Rölling and van de Fliert 1994). During periods of drought and harvest failure, wealthy farmers function to buffer the impacts through lending money, providing temporary employment, and marketing peasant products (Husken 1989). The government acts to reduce the intensity of shocks for the urban poor through price stabilization in the domestic market and rice subsidies (Neilson and Arifin 2012). Furthermore, the peasants and urban poor have adapted to the shocks by pooling resources as a poverty-sharing mechanism (Irhamni and Nuryakin 2009). Such adaptations, as active efforts of the society to survive (Bohle et al. 2009), demonstrate how resilience is manifested as human agency and intentionality. They do not, however, fully explain the capacity of the SES to retain its function despite recurring exposure of the most vulnerable to hunger and the dominance of large-scale monocrops that are dependent on inputs of chemicals.

\section{The New Zealand kiwifruit industry}

Kiwifruit also holds an important socioeconomic role for New Zealanders. It is the largest horticultural industry in New Zealand, and its product is positioned as an "upmarket fruit category" (Beverland 2001) with great promise to contribute to economic growth. According to FreshFacts (2011), most of the country's kiwifruit is oriented towards the export market, comprising more than $90 \%$ of total production. In 2006, kiwifruit comprised $60 \%$ of total fruit exports and 30\% of total earnings in the country's horticultural exports (Kilgour et al. 2008).

Over the last 100-odd years, the growth of the New Zealand kiwifruit industry has been extraordinary. Two momentous periods exemplify this outstanding growth, separated by a series of crises that brought the industry near collapse. The first period of growth in the late 1970s reflected the early acceptance of kiwifruit in international markets and the subsequent rapid increase in plantations, production, and export earnings. Between 1981 and 1983 , there was an increase of nearly $70 \%$ of the total plantation area worldwide, $52 \%$ of which occurred in New Zealand (Kernohan and Sale 1983).

This growth trajectory was interrupted by a series of crises in the late 1980 s and early 1990s. The combination of economic deregulation, anti-dumping charges from California-based growers, oversupply and declining prices, and the detection of pesticide residue on fruit exported to Italy nearly led the industry to collapse. In 1997, in response to this situation, the industry initiated a restructuring of the industry centered on a growerowned, single-desk marketing organization (ZESPRI International, henceforth Zespri). The commitment to cooperative marketing also established the basis for restructuring orchard management through mandatory integrated pest management protocols and, in some cases, conversion to organic practices (Campbell and Fairweather 1998). The following year, New Zealand kiwifruit was rebranded as an environmentally friendly commodity produced under a $100 \%$ compliance with the integrated pest management protocols (Rosin et al. 2008). With its differentiated products and strict quality controls, the industry was able to earn a price premium in export markets, triggering incremental increases in production over the past 10 years (Kilgour et al. 2008). In adaptive cycle terms, this was the second exploitative growth phase for the industry.

In this instance as well, human intentionality is commonly identified as the sole factor in the re-emergence of the industry and as evidence of the industry's transformative resilience. The influence of humans and human institutions on the resilience of the SES is obvious (Darnhofer et al. 2010, Rosin et al. 2012). At the industry level, Zespri is acknowledged as a leader with a vision for the future of the kiwifruit industry. This elevates trust among the industry's stakeholders. At the orchard level, strong leadership was shown by several growers as they developed a long-term vision of their orchards. The stakeholders also show their capacity for self-organization, facilitated through well-established communication channels between Zespri, kiwifruit growers, pack houses, and consultants. These features are recognized as critical aspects in building resilience (Folke et al. 2002). The recent appearance of a vine-killing bacterial disease that threatens the viability of the industry suggests, however, that these qualities of human agency may be insufficient to accurately assess the resilience of the SES. 
Table 2. Values of different perspectives in assessing the resilience of the two case studies.

\begin{tabular}{|c|c|c|c|}
\hline & System perspective & Human agency perspective & Actor-network perspective \\
\hline $\begin{array}{c}\text { Indonesia's rice } \\
\text { agriculture }\end{array}$ & $\begin{array}{l}\text { The system has shown to be resilient in } \\
\text { the face of a multitude of shocks over } \\
\text { the course of the system development }\end{array}$ & $\begin{array}{l}\text { Actors adapt to shocks through } \\
\text { knowledge (local and scientific), } \\
\text { diversity, and social capital }\end{array}$ & $\begin{array}{l}\text { Resilience is influenced by the fluidity of } \\
\text { rice within the society by which adaptive } \\
\text { capacity is strengthened; resilience } \\
\text { manifests as fast-adaptation at multiple } \\
\text { levels }\end{array}$ \\
\hline $\begin{array}{l}\text { The New Zealand } \\
\text { kiwifruit industry }\end{array}$ & $\begin{array}{c}\text { The system undergoes transformations } \\
\text { while showing its resilience to global } \\
\text { shocks }\end{array}$ & $\begin{array}{l}\text { Actors (growers, packing houses, } \\
\text { marketers) are maintaining a good } \\
\text { communication channel and showing } \\
\text { good leadership that contribute to the } \\
\text { industry's resilience }\end{array}$ & $\begin{array}{l}\text { Resilience is influenced (enhanced/ } \\
\text { hampered) by the durability of kiwifruit } \\
\text { which builds into the robustness of the } \\
\text { industry; resilience is performed through } \\
\text { long-term management planning }\end{array}$ \\
\hline
\end{tabular}

\section{DISCUSSION}

Both the rice and kiwifruit case studies provide insight into the role of agency in SESs. Both offer evidence of the potential for human agency and intentionality to influence the resilience of a system either through reinforcing social structures and governance in the conservation phase or through innovation and experimentation in the reorganization phase. Yet, each also challenges an exclusive focus on human agency in SES research, which fails to satisfactorily explain the concurrence of brittleness and resilience manifest in the case studies. We believe this raises valuable questions regarding the other entities that influence the capacity of these human actors to maintain and extend their resilience to the whole SES, lending insight into how and why people do what they do in building resilience. In Table 2, we illustrate how the different conceptions of agency offer complementary understandings of the ways in which both rice and kiwifruit systems perform resilience, with adaptation strategies in each influenced by the materiality of rice and kiwifruit through their respective fluidity and durability.

Taking the lead from ANT, we argue that system resilience is equally influenced (i.e., reinforced or hampered) by the capacity of rice and kiwifruit, as nonhuman actants, to respond to shocks. As we will illustrate shortly, rice is central to the adaptive capacity of the communities at both ends of the supply chain due, in part, to its fluidity (de Laet and Mol 2000). Here, fluidity refers to the capacity of rice, as an object and symbol, to connect to a wide variety of actants. Kiwifruit, on the other hand, has the potential to increase, but also hamper, resilience through its durability (Law 2008), or the capacity of actants to maintain the robustness and stability of the network over time and across space.

\section{The agency of rice as a fluid object}

In terms of its contribution to the resilience of the SES, rice's agency is rooted in its fluidity. As a crop, rice is able to adapt to most environments ranging from dry uphill areas at the foot of the Himalayas to deep pools of water in lowland tropical Asia (Hanks 1972). With more than 112,000 varieties that have interchangeable traits and properties (Huang et al. 2012), rice has the capacity to express desirable characteristics, including pest resistance, tolerance to extreme environments, preferred taste qualities, and high yield.

At a regional level, the fluidity of rice enables the International Rice Research Institute to develop rice varieties that can exploit a greater range in environmental variation (Herdt and Capule 1983). There have been numerous studies identifying genetic traits of rice that express increased tolerance to climate change impacts such as drought, inundation, salinity, and pests (Wassman et al. 2009, Ismail et al. 2010, Mackill et al. 2010). Although these varieties are the result of extensive research and innovation (thus demonstrating human intentionality), these researchers also recognize the unique features of rice as a reinforcing factor of the adaptation process (Wassman et al. 2009). These varieties, in combination with better farming techniques and infrastructure, increase the flexibility of rice farming systems and contribute to their resilience to extreme climatic shocks.

At a broader scale, the fluidity of rice involves more than genetic diversity. Rice is also deeply entangled in the life of farmers in Asia through millennia of co-evolution between people, environments, and rice (Hanks 1972, Gerard et al. 2001). Lucien Hanks (1972:18), in his book Rice and Man, wrote:

As rice cultivation spread, each new field with its peculiar
qualities of light, moisture, temperature, and soil set the
conditions for advantageous mutations and directions of
variation. Year after year each locality of cultivators
selected the handsomest, the tastiest, and the most
sweetly perfumed to plant in the coming year. Where
settlement or strain of seed remained stable, there
developed the special virtues that characterize each
variety, bearing the scars of drought and epidemic, the
shape and color that please.

In this manner, rice influences how local communities perform agency and thus increase their resilience in the face of environmental shocks. For instance, Soemarwoto (2007) documents how a traditional community in Java continuously discovers new rice varieties during every harvest period. These farmers then utilize the increasing number of the local varieties to adapt to environmental shocks such as climate variations and pest infestations. In assuming more than 500 varietal forms, rice greatly enhances the community's ability to adjust farming practices to changing climatic conditions. The diverse sensitivity of rice varieties to competition for other food and tree crops allows farmers to practice mixed-crop farming strategies. By establishing these relationships with human actors, rice provides the community with greater adaptive capacity, a factor associated with stronger community resilience (Berkes and Ross 2013). 
The narrative suggests that the full capacity of Indonesian society for building resilience would not transpire without the relational agency of humans and rice. Humans respond to shocks by relying, to some extent, on the fluidity of rice. This fluidity (i.e., the materiality of rice that enables humans to flexibly adjust their farming strategies) provides a relatively fast adaptation process to new emerging types of shocks, both at the local and regional levels. Over time, this reliance has become normalized to the extent that they (and we) fail to recognize the agency of rice. However, the specific crop-people relationality underlying SES resilience processes in rice farming does not necessarily translate to other types of agricultural commodity systems - for example, kiwifruit-where different actor-networks result in entirely different ways of building (or even damaging) resilience.

\section{The agency of kiwifruit as a durable matter}

In addition to the role of nonhuman agency in the persistence of the SES, acknowledging the agency of kiwifruit in New Zealand provides insight into the system's vulnerability. In this case, we again argue that the relative resilience of the kiwifruit system cannot be attributed solely to its human actants. On one hand, a deeper examination of the agency of kiwifruit shows that, in conjunction with other actants, kiwifruit renders the industry durable and resilient to economic shocks. Resilience of the industry to economic shocks in the past four decades was influenced by the durability of the fruit and the vines. The physical and chemical characteristics of the "Hayward" green kiwifruit make it the perfect participant in a global distribution network located in New Zealand. It can be picked before it is mature and resistant to bruising, and then can remain in desirable eating condition for a long time when kept in cool storage. This material durability is the basis for the stability and growth of the industry. The investment potential associated with kiwifruit further played a role in attracting more people to establish orchards and to develop the complex marketing and distribution structure that contributes to robustness of the industry.

On the other hand, the relational agency of humans and kiwifruit also compromises the resilience of the SES. For example, the perennial nature of the kiwifruit vine and the fact that it grows and produces a profitable harvest over several decades allows it to enroll orchardists eager to exploit the investment opportunity. That the crop requires seven to nine years to reach full production (Morley-Bunker and Lyford 1999), however, exposes the orchardist to significant financial risk during initial stages of orchard establishment. As a result, the level of sunk capital invested in the industry is so high that it creates excessive stability (or a lock-in trap; Allison and Hobbs 2004), preventing the system from flipping to a more desirable state. In this manner, kiwifruit plays an active role in both the industry's exponential growth and, to some extent, the compromised adaptive capacity of the human actors.

The recent appearance of a debilitating bacterial disease in New Zealand kiwifruit orchards exemplifies the implications of this loss of resilience in the face of environmental shocks. On 3 November 2010, a Te Puke orchardist detected spotty leaves and oozing white and red fluid from the vines, which eventually resulted in a cane dieback. The bacteria causing this disease are called Pseudomonas syringae pv. actinidiae (Psa). Vanneste et al. (2011) document a wet and cold spring that helps the Psa to proliferate and disseminate locally across orchards by creating a humid environment.

Psa, along with the relational effect shaped with kiwifruit and people within the industry, disrupted the solid network that the industry had built for decades. Regardless of the strong leadership that Zespri has shown, good communication channels being built, and the use of scientific and tacit knowledge or a diversity of orchards and practices, the resilience of the industry in the face of Psa is still questioned. One reason is the extent to which kiwifruit (and Psa) remain incomprehensible to the people within the industry. The disease and the kiwifruit are relatively novel to the industry; therefore, no one knows for sure how these vibrant actants would react in the future. The search for new Psa-tolerant kiwifruit varieties might take another 5-10 years, and during that period, the industry may become more vulnerable to shocks. The durability of kiwifruit (i.e., the materiality of kiwifruit that enables humans to invest and plan for long-term goals) influences the way in which resilience is enacted as a long-term centralized management plan that incorporates the uncertainties of the crop as an important equation.

\section{CONCLUSION}

Both Indonesia's rice agriculture and the New Zealand kiwifruit industry demonstrate strong aspects of resilience. However, the factors that contribute to this resilience are still subject to multiple interpretations. The context provided for the two cases shows that resilience can operate either as a system property (i.e., both cases demonstrate resilient and adaptive agricultural systems in the face of various shocks) or in the agency of individuals and society to adapt to shocks. From the perspective of human intentionality, these characteristics provide the basis for narratives in which resilience is solely the product of the ingenuity and action of human actors. We argue, however, that an ANT perspective offers a different understanding of resilience by focusing on the relational effect shaped by the interaction of humans and nonhumans. By recognizing that nonhumans (e.g., crops, technology, climate) are not mere passive objects to be utilized or managed in the pursuit of resilience, we become aware of the capacity for "vibrant" matter to both reinforce and impede the resilience of an SES and to shape the manner in which the adaptive capacity of humans is expressed. Here, it is important to note that nonhuman agency does not mean that these actants have tendencies like humans, nor do they express intentionality. Instead, acknowledging that actants (both human and nonhuman) have the capacity to influence the configuration of an SES awakens our awareness to the fact that the ability of humans to perform agency and build resilience is dependent upon the specific relationalities between them and the nonhuman components.

By complementing more traditional views of agency with that of ANT, we widen our lens and begin to perceive the agency of nonhumans and their relational effects on human intentionality. This perspective shifts our focus to the particularities of the local system in which resilience is enacted and managed. As suggested by Kwa (2002), such a network approach requires us to pay less attention to universal patterns and more to local contingencies. The relationality within SESs is different in each locale, and this condition underlies the failure in applying uniform guidelines of building resilience to different communities (Berkes and Ross 
2013). In the end, human adaptive capacity and the resilience of an SES are influenced by many factors: the vibrancy of the nonhumans (crops, diseases, or other types of shocks), the extent to which the heterogeneous network is maintained, and the relationships that are developed with a wider set of actants (e.g., climate, technology, markets). As much as the future trajectory of biophysical processes are uncertain, the way society responds to this uncertainty is also contingent on the possible relationships shaped by these actants. In a practical sense, acknowledging agency beyond human intentionality extends our focus from the adaptive capacity of individual humans to their alignment with the rest of the actants in the network and the constraints and opportunities posed by the nature and character of these nonhuman actants.

Responses to this article can be read online at: http://www.ecologyandsociety.org/issues/responses. php/6805

\section{Acknowledgments:}

This research was conducted as part of the doctoral study of one of the co-authors, and was supported partly by the NZAid Development Scholarship and the ARGOS Research Project. We would like to thank the participants of this study for providing valuable information for this research. We would also like to thank the Subject Editor and two anonymous reviewers for their very helpful comments.

\section{LITERATURE CITED}

Adger, W. N. 2000. Social and ecological resilience: are they related? Progress in Human Geography 24:347-364. http://dx.doi. org/10.1191/030913200701540465

Allison, H. E., and R. J. Hobbs. 2004. Resilience, adaptive capacity, and the "lock-in trap" of the Western Australian agricultural region. Ecology and Society 9(1):3. [online] URL: http://www.ecologyandsociety.org/vo19/iss 1/art3/

Badan Pusat Statistik (BPS). 2013. Statistik Indonesia. [online] URL: http://www.bps.go.id/

Bandura, A. 2001. Social cognitive theory: an agentic perspective. Annual Review of Psychology 52(1):1-26. http://dx.doi. org/10.1146/annurev.psych.52.1.1

Bennett, J. 2007. Edible matter. New Left Review 45:133.

Berkes, F., and H. Ross. 2013. Community resilience: toward an integrated approach. Society \& Natural Resources 26:5-20. http:// dx.doi.org/10.1080/08941920.2012.736605

Beverland, M. 2001. Creating value through brands: the ZESPRI kiwi fruit case. British Food Journal 103:383-399. http://dx.doi. org/10.1108/00070700110400389

Bohle, H.-G., B. Etzold, and M. Keck. 2009. Resilience as agency. International Human Dimension Programme Update 2:8-13.

Bourdieu, P. 1977. Outline of a theory of practice. Cambridge University Press, New York, USA. http://dx.doi.org/10.1017/ CBO9780511812507
Bottomore, T. B., and R. A. Nisbet. 1978. A history of sociological analysis. Basic Books, New York, USA.

Braun, B. 2005. Environmental issues: writing a more-thanhuman urban geography. Progress in Human Geography 29:635650 .

Brown, K., and E. Westaway. 2011. Agency, capacity, and resilience to environmental change: lessons from human development, well-being, and disasters. Annual Review of Environment and Resources 36:321-342. http://dx.doi.org/10.1146/ annurev-environ-052610-092905

Callon, M. 1986. Some elements of a sociology of translation: domestication of the scallops and the fishermen of St Brieuc bay. In J. Law, editor. Power, action and belief: a new sociology of knowledge? Routledge, London, UK.

Campbell, H., and J. R. Fairweather. 1998. The development of organic horticultural exports in New Zealand. Agribusiness and Economics Research Unit (AERU), Lincoln University, Christchurch, New Zealand.

Clements, F. E. 1916. Plant succession: an analysis of the development of vegetation. Carnegie Institution of Washington, Washington, D.C., USA. http://dx.doi.org/10.5962/bhl.title.56234

Colinvaux, P. 1973. Introduction to ecology. John Willey \& Sons, New York, USA.

Cote, M., and A. J. Nightingale. 2012. Resilience thinking meets social theory: situating social change in socio-ecological systems (SES) research. Progress in Human Geography 36:475-489. http:// dx.doi.org/10.1177/0309132511425708

Coulthard, S. 2012. Can we be both resilient and well, and what choices do people have? Incorporating agency into the resilience debate from a fisheries perspective. Ecology and Society 17(1):4. http://dx.doi.org/10.5751/ES-04483-170104

Darnhofer, I., J. Fairweather, and H. Moller. 2010. Assessing a farm's sustainability: insights from resilience thinking. International Journal of Agricultural Sustainability 8:186-198. http://dx.doi.org/10.3763/ijas.2010.0480

Davidson, D. J. 2010. The applicability of the concept of resilience to social systems: some sources of optimism and nagging doubts. Society \& Natural Resources 23:1135-1149. http://dx.doi. org/10.1080/08941921003652940

Davidson-Hunt, I. J., and F. Berkes. 2002. Nature and society through the lens of resilience: toward a human-in-ecosystem perspective. Pages 53-82 in F. Berkes, J. Colding, and C. Folke, editors. Navigating social-ecological systems: building resilience for complexity and change. Cambridge University Press, Cambridge, UK. http://dx.doi.org/10.1017/CBO9780511541957.006

Dawe, D. 2002. The changing structure of the world rice market, 1950-2000. Food Policy 27:355-370. http://dx.doi.org/10.1016/ $\underline{\text { S0306-9192(02)00038-6 }}$

de Laet, M., and A. Mol. 2000. The Zimbabwe Bush Pump: mechanics of a fluid technology. Social Studies of Science 30:225263. http://dx.doi.org/10.1177/030631200030002002 
Dwiartama, A. 2014. Investigating resilience of agriculture and food systems: insights from two theories and two case studies. Dissertation. University of Otago, New Zealand.

Fernando, C. H. 1993. Rice field ecology and fish culture: an overview. Hydrobiologia 259:91-113. http://dx.doi.org/10.1007/ $\underline{\mathrm{BF} 00008375}$

Folke, C. 2006. Resilience: the emergence of a perspective for social-ecological systems analyses. Global Environmental ChangeHuman and Policy Dimensions 16:253-267. http://dx.doi. org/10.1016/j.gloenvcha.2006.04.002

Folke, C., J. Colding, and F. Berkes. 2002. Synthesis: building resilience and adaptive capacity in social-ecological systems. Pages 352-387 in F. Berkes, J. Colding, and C. Folke, editors. Navigating social-ecological systems: building resilience for complexity and change. Cambridge University Press, Cambridge, UK. http://dx.doi.org/10.1017/CBO9780511541957.020

FreshFacts. 2011. New Zealand horticulture 2011. New Zealand Institute for Plant \& Food Research Ltd., Auckland, New Zealand.

Gerard, F., I. Marty, and Erwidodo. 2001. The 1998 food crisis: temporary blip or the end of food security? In F. Gerard and F. Ruf, editors. Agriculture in crisis: people, commodities, and natural resources in Indonesia, 1996-2000. CIRAD, Montpellier, France.

Giddens, A. 1984. The constitution of society: outline of the theory of structuration. University of California Press, Berkeley, California, USA.

Gleason, H. A. 1926. The individualistic concept of the plant association. Bulletin of the Torrey Botanical Club 53:7-26. http:// dx.doi.org/10.2307/2479933

Gunderson, L., and C. S. Holling, editors. 2002. Panarchy: understanding transformations in human and natural systems. Island Press, Washington, D.C., USA.

Hanks, L. M. 1972. Rice and man: agricultural ecology in Southeast Asia. Adline and Atherton Inc., Chicago, Illinois, USA.

Herdt, R. W., and C. Capule. 1983. Adoption, spread, and production impact of modern rice varieties in Asia. International Rice Research Institute, Manila, Philippines.

Huang, X., N. Kurata, X. Wei, Z.-X. Wang, A. Wang, Q. Zhao, Y. Zhao, K. Liu, H. Lu, W. Li, et al. 2012. A map of rice genome variation reveals the origin of cultivated rice. Nature 490:497-501. http://dx.doi.org/10.1038/nature11532

Husken, F. 1989. Cycles of commercialization and accumulation in a central Javanese village. In G. Hart, A. Turton, B. White, B. Fegan, and L. T. Gheen, editors. Agrarian transformations: local processes and the state in Southeast Asia. University of California Press, Berkeley, California, USA.

Irhamni, M., and C. Nuryakin. 2009. The rice sector in West Java. In A. L. Stoler, J. Redden, and L. A. Jackson, editors. Trade and poverty reduction in the Asia-Pacific region. WTO and Cambridge University Press, Cambridge, UK.

Ismail, A. M., M. J. Thomson, G. V. Vergara, M. A. Rahman, R. K. Singh, G. B. Gregorio, and D. J. Mackill. 2010. Designing resilient rice varieties for coastal deltas using modern breeding tools. Chapter 12. in C. T. Hoanh, B. W. Szuster, S. Kam, A. M.
Ismail, and A. D. Noble, editors. Tropical deltas and coastal zones: food production, communities and environment at the land and water interface. CABI International, Cambridge, Massachusetts, USA. http://dx.doi.org/10.1079/9781845936181.0154

Keil, A., M. Zeller, A. Wida, B. Sanim, and R. Birner. 2008. What determines farmers' resilience towards ENSO-related drought? An empirical assessment in Central Sulawesi, Indonesia. Climatic Change 86:291-307. http://dx.doi.org/10.1007/s10584-007-9326-4

Kernohan, C. M., and P. Sale. 1983. The New Zealand kiwifruit industry 1983. Technical Report 5/83. New Zealand Ministry of Agriculture and Fisheries, Wellington, New Zealand.

Kilgour, M., C. Saunders, F. Scrimgeour, and E. Zellman. 2008. The key elements of success and failure in the NZ kiwifruit industry. Agribusiness and Economics Research Unit (AERU), Lincoln University, Christchurch, New Zealand.

Kwa, C. 2002. Romantic and baroque conceptions of complex wholes in the sciences. Pages 23-52 in J. Law and A. Mol, editors. Complexities: social studies of knowledge practices. Duke University Press, Durham, UK.

Latham, A. J. H., and L. Neal. 1983. The international market in rice and wheat, 1868-1914. Economic History Review 36:260-280.

Latour, B. 1987. Science in action: how to follow scientists and engineers through society. Harvard University Press, Cambridge, Massachusetts, USA.

Latour, B. 2005. Reassembling the social: an introduction to actornetwork-theory. Oxford University Press, Oxford, UK.

Law, J. 1986. On the methods of long-distance control: vessels, navigation and the Portuguese route to India. Pages 234-263 in J. Law, editor. Power, action and belief: a new sociology of knowledge? Routledge, London, UK.

Law, J. 1992. Notes on the theory of the actor-network: ordering, strategy, and heterogeneity. Systems Practice 5:379-393. http:// dx.doi.org/10.1007/BF01059830

Law, J. 2008. Actor Network Theory and material semiotics. Chapter 7 in B. S. Turner, editor. The new Blackwell companion to social theory. John Willey \& Sons, New York, USA.

Levin, S. 1999. Fragile dominion: complexity and the commons. Perseus Publishing, New York, USA.

Lister, R. 2004. Poverty. Polity, Cambridge, UK.

Long, N., and J. D. van der Ploeg. 1994. Heterogeneity, actor and structure: towards a reconstitution of the concept of structure. In D. Booth, editor. Rethinking social development: theory, research and practice. Longman Scientific and Technical, Essex, UK.

Mackill, D. J., A. M. Ismail, A. M. Pamplona, D. L. Sanchez, J. J. Carandang, and E. Septiningsih. 2010. Stress tolerant rice varieties for adaptation to a changing climate. Crop, Environment, \& Bioinformatics 7:250-259.

Marks, D. 2010. Unity or diversity? On the integration and efficiency of rice markets in Indonesia, c. 1920-2006. Explorations in Economic History 47:310-324. http://dx.doi.org/10.1016/j. eeh.2009.08.002 
Morley-Bunker, M., and P. Lyford. 1999. Kiwifruit. Chapter 18. in D. Jackson, N. E. Looney, M. Morley-Bunker, and G. F. Thiele, editors. Temperate and subtropical fruit production. CABI Publishing, New York, USA.

Murdoch, J. 1998. The spaces of actor-network theory. Geoforum 29:357-374. http://dx.doi.org/10.1016/S0016-7185(98)00011-6

Neilson, J., and B. Arifin. 2012. Food security and the deagrarianisation of the Indonesian economy. In C. Rosin, H. Campbell, and P. Stock, editors. Food systems failure: the global food crisis and the future of agriculture. Earthscan Press, London, UK.

Olsson, P., C. Folke, and T. Hahn. 2004. Social-ecological transformation for ecosystem management: the development of adaptive co-management of a wetland landscape in southern Sweden. Ecology and Society 9(4):2. [online] URL: http://www. ecologyandsociety.org/vo19/iss4/art2/

Pelling, M., and D. Manuel-Navarrete. 2011. From resilience to transformation: the adaptive cycle in two Mexican urban centers. Ecology and Society 16(2):11. [online] URL: http://www. ecologyandsociety.org/vol16/iss2/art11/

Röling, N., and E. van de Fliert. 1994. Transforming extension for sustainable agriculture: the case of integrated pest management in rice in Indonesia. Agriculture and Human Values 11:96-108. http://dx.doi.org/10.1007/BF01530451

Rosin, C., H. Campbell, and L. Hunt. 2008. Audit me this! Kiwifruit producer uptake of the EurepGAP audit system in New Zealand. In C. Stringer and R. Le Heron, editors. Agri-food commodity chains and globalising networks. Ashgate, Aldershot, UK.

Rosin, C., A, Dwiartama, L. M. Hunt, and S. Van den Dungen. 2012. Resilience in retrospective: analysis of response to shocks and stress in the New Zealand kiwifruit and sheep and beef sectors. Research Report: Number 12/08. ARGOS, Dunedin, New Zealand.

Ross, H., and F. Berkes. 2013. Community resilience: a rejoinder to Debra J. Davidson. Society \& Natural Resources 26(1):25-29. http://dx.doi.org/10.1080/08941920.2012.749769

Soemarwoto, R. 2007. Kasepuhan rice landrace diversity, risk management, and agricultural modernization. In R. Ellen, editor. Modern crises and traditional strategies: local ecological knowledge in island Southeast Asia. Berghahn Books, New York, USA.

Vanneste, J., C. Kay, R. Onorato, J. Yu, D. Cornish, F. Spinelli, and S. Max. 2011. Recent advances in the characterisation and control of Pseudomonas syringae pv. actinidiae, the causal agent of bacterial canker on kiwifruit. In G. Costa and A. R. Ferguson, editors. Proceedings of the Seventh International Symposium on Kiwifruit, 12-17 September 2010. International Society for Horticultural Science, Leuven, Belgium.
Walker, B., S. Carpenter, J. M. Anderies, N. Abel, G. Cumming, M. A. Janssen, L. Lebel, J. Norberg, G. D. Peterson, and R. Pritchard. 2002. Resilience management in social-ecological systems: a working hypothesis for a participatory approach. Conservation Ecology 6(1):14.

Walker, B., C. S. Holling, S. R. Carpenter, and A. Kinzig. 2004. Resilience, adaptability and transformability in social-ecological systems. Ecology and Society 9(2):5. [online] URL: http://www. ecologyandsociety.org/vol9/iss2/art5/

Walsh, F. 1998. Strengthening family resilience. Guilford Press, New York, USA.

Wassmann, R., S. V. K. Jagadish, S. Heuer, A. Ismail, E. Redona, R. Serraj, R. K. Singh, G. Howell, H. Pathak, and K. Sumfleth. 2009. Climate change affecting rice production: the physiological and agronomic basis for possible adaptation strategies. Pages 59 122 in D. L. Sparks, editor. Advances in agronomy, Vol 101. Academic Press, Burlington, Massachusetts, USA.

Wessing, R. 1988. Spirits of the earth and spirits of the water: chthonic forces in the mountains of West Java. Asian Folklore Studies 47:43-61. http://dx.doi.org/10.2307/1178251

Westley, F., S. Carpenter, W. A. Brock, C. S. Holling, and L. Gunderson. 2002. Why systems of people and nature are not just social and ecological Systems. In L. Gunderson and C. S. Holling, editors. Panarchy: understanding transformations in human and natural systems. Island Press, Washington, D.C., USA. 